\title{
How women perceive abortion care: A study focusing on healthy women and those with mental and posttraumatic stress
}

Inger Wallin Lundell, Susanne Georgsson Ohman, Inger Sundstrom Poromaa, Ulf Hogberg,

Gunilla Sydsjö and Agneta Skoog Svanberg

\section{Linköping University Post Print}

\section{Tweet}

N.B.: When citing this work, cite the original article.

Original Publication:

Inger Wallin Lundell, Susanne Georgsson Ohman, Inger Sundstrom Poromaa, Ulf Hogberg, Gunilla Sydsjö and Agneta Skoog Svanberg, How women perceive abortion care: A study focusing on healthy women and those with mental and posttraumatic stress, 2015, European journal of contraception \& reproductive health care, (20), 3, 211-222. http://dx.doi.org/10.3109/13625187.2014.1002032

Copyright: Informa Healthcare http://informahealthcare.com/

Postprint available at: Linköping University Electronic Press http://urn.kb.se/resolve?urn=urn:nbn:se:liu:diva-120060 
How do women perceive abortion care: A study focusing on healthy women and those with mental and posttraumatic stress

Inger Wallin Lundell ${ }^{1,2}$, Susanne Georsson Ohman ${ }^{2,3}$, Inger Sundstrom Poromaa ${ }^{1}$, Ulf Hogberg $^{1}$, Gunilla Sydsjo ${ }^{4}$ and Agneta Skoog Svanberg ${ }^{1}$

${ }^{1}$ Department of Women's and Children's Health, Uppsala University, Uppsala, Sweden

${ }^{2}$ Sophiahemmet University, Stockholm, Sweden

${ }^{3}$ Department of Women's and Children's Health, Karolinska Institutet, Stockhom, Sweden

${ }^{4}$ Division of Obstetrics and Gynecology, Department of Clinical and Experimental Medicine Faculty of Health Sciences, Linköping University, SE581 85 Linköping, Sweden

Short title: Perceptions of abortion care and mental stress

Key Words: Abortion; Ambulatory care facilities; Stress disorders; Posttraumatic stress Disorders; Anxiety; Depression

Correspondence: Dr. Inger Wallin Lundell, Department of Women's and Children's Health, Uppsala University, SE 75185 Uppsala, Sweden. Tel: +46 (0)70 162 1029, Fax: +46 (0)18 559775. Email: inger.wallinlundell@shh.se 


\section{Abstract}

Objectives To identify perceived deficiencies in the quality of abortion care among healthy women and those with mental stress.

Methods This multi-centre cohort study included six obstetrics and gynaecology departments in Sweden. Posttraumatic stress (PTSD/PTSS) was assessed using the Screen QuestionnairePosttraumatic Stress Disorder; anxiety and depressive symptoms, using the Hospital Anxiety Depression Scale; and abortion quality perceptions, using a modified version of the Quality from the Patient's Perspective questionnaire. Pain during medical abortion was assessed in a subsample using a visual analogue scale.

Results Overall, $16 \%$ of the participants assessed the abortion care as being deficient, and $22 \%$ experienced intense pain during medical abortion. Women with PTSD/PTSS more often perceived the abortion care as deficient overall and differed from healthy women in reports of deficiencies in support, respectful treatment, opportunities for privacy and rest, and availability of support from a significant person during the procedure. There was a marginally significant difference between PTSD/PTSS and the comparison group for insufficient pain alleviation.

Conclusions Women with PTSD/PTSS perceived abortion care to be deficient more often than did healthy women. These women do require extra support, relatively simple efforts to provide adequate pain alleviation, support and privacy during abortion may improve abortion care. 


\section{Introduction}

In the few studies that have evaluated women's perspectives of abortion care demonstrate that women in different countries rate their overall satisfaction with abortion care as high ${ }^{1-6}$. When women are dissatisfied or report negative experiences of abortion care, it was reported to be because of multiple factors including patient-related factors such as pain experiences, expectations of care and sociodemographics in previous studies ${ }^{2}$. Younger women ${ }^{1,2,6}$, women with higher levels of education ${ }^{2}$ and women without children ${ }^{1,6}$ were more likely to report negative experiences of abortion care. Experiences of long waiting time ${ }^{2,5,7}$,

inadequacies in treatment by clinicians and health care $\operatorname{staff}^{2,3,5,7}$ and medical complications in relation to the abortion ${ }^{1}$ are examples of health care-related factors. One researcher suggested that to increase satisfaction with abortion services for women undergoing surgical abortion the waiting time at the clinic should be shortened ${ }^{7}$. For women having medical abortion, the provision of adequate and realistic information about bleeding, pain, expulsions and related factors is important and has been stressed in several studies ${ }^{3-6}$.

Medical abortions can be performed at home, and the number of such practices appears to be increasing in Sweden $^{8}$, although exact data are unavailable 9 . Midwives are now performing the duties of drug administration, care during the procedure and follow-up ${ }^{10}$. Barbarosa suggests that routine assessments of patient satisfaction could help health care staff to identify those in need of more support ${ }^{11}$.

Previously, in a longitudinal study, we investigated the prevalence of posttraumatic stress disorder (PTSD) and posttraumatic stress symptoms (PTSS) in abortion-seeking women. The prevalence of PTSD before the abortion was 7\%, which is consistent with the general Swedish female population ${ }^{12}$, and the prevalence of PTSS was $23 \%^{13}$. However, no population based figures for PTSS were available in the study of Frans and colleagues ${ }^{12}$. 
It is important to identify women with mental stress, including not only those with PTSD/PTSS, but also those who present at the abortion clinic with anxiety and/or depressive symptoms, because some of these women may be in need of counselling to prevent negative experiences and dissatisfaction. However, it is unknown specifically which aspects of the abortion care, in addition to counselling, may be improved for women with adverse mental health. Thus, the aim of the present study was to identify perceived deficiencies in the quality of abortion care, focusing on the perceptions of women who present with mental stress at the abortion clinic as compared with women who did not show the specific symptoms of mental distress for which we measured.

\section{Methods}

This study is a part of a multi-centre cohort study targeting women who requested an induced abortion from September 2009 to June 2010 at the outpatient clinics of the gynaecology and obstetrics departments of six public hospitals in Sweden. All women who requested an induced abortion before the end of the $12^{\text {th }}$ gestational week were approached for participation. The only exclusion criterion was the inability to read and understand Swedish ${ }^{13}$. Women were informed about the study, including the follow-ups, at the first abortion visit. Participating women signed an informed consent form and completed the first questionnaire in the waiting room at the abortion clinic before they underwent abortion. Two follow-up questionnaires were sent by post to the participating women at 3 and 6 months after the abortion $^{14}$. The study was approved by the Regional Ethics Committee of Uppsala University, Uppsala, Sweden (approval date February 25, 2009).

\section{Measurements}

The following instruments were used: the Screen Questionnaire-Posttraumatic Stress Disorder (SQ-PTSD) ${ }^{12}$, the Hospital Anxiety and Depression Scale (HADS) $)^{15}$ and the Quality from the 
Patient's Perspective (QPP) questionnaire ${ }^{16,17}$. The baseline questionnaire also collected data on sociodemographic variables. Supplementary information, including previous pregnancy, abortion method, place of abortion (home or outpatient clinic) and psychosocial support during the abortion process, was retrieved from the patients' medical records. Intensity of pain was measured using the visual analogue scale (VAS, ranging from $0=$ no pain to $10=$ worst possible pain) in a subsample $(\mathrm{n}=128)$ who had medical abortions at the Umeå University hospital outpatient clinic.

\section{$S Q-P T S D$}

The SQ-PTSD ${ }^{12}$ was used to obtain a diagnosis of PTSD and of PTSS based on self-reported data. Data from the baseline assessment were analysed to assign a research diagnosis of PTSD/PTSS to women at the time of their abortion. The instrument is based on the Diagnostic and Statistical Manual of Mental Disorders, Fourth Edition (DSM-IV) diagnostic criteria for PTSD $^{18}$ and assesses trauma experiences as well as trauma symptoms ${ }^{12}$. Only women who met all the DSM-IV criteria from A to F were classified as having a research diagnosis of lifetime PTSD. In previous studies, different terms have been used to denote individuals who only partly met the diagnostic criteria: sub-threshold PTSD, partial PTSD or PTSS ${ }^{19}$. In the present study, we used the term PTSS.

\section{HADS}

The HADS measures anxiety and depressive symptoms and contains 14 items divided into two scales: seven items evaluating anxiety and seven evaluating depressive symptoms ${ }^{15}$. The instrument has been validated in several clinical populations with satisfactory results ${ }^{20}$, including in Swedish circumstances ${ }^{21}$. Data from the baseline assessment were analysed to evaluate whether anxiety and/or depressive symptoms were present at the time of abortion. 


\section{$Q P P$}

Perceived quality of care at the abortion clinic was evaluated at 3-month follow-up by use of selected questions from the QPP questionnaire. The instrument was included in the questionnaire for the 3-month assessment, because we decided to evaluate the abortion care as close as possible after the abortion, trying to minimize recall bias. According to the QPP, quality of care can be understood in the light of two conditions: the resource structure of the care organisation and the patient's preferences. The first condition consists of person-related, physical and administrative qualities, and the latter has both rational and human aspects. The QPP for outpatient clinics contains 21 items ${ }^{16}$.

The present study used a modified version of the QPP questionnaire, containing 18 items, inspired by a previous abortion study ${ }^{5}$. Additionally, the phrasing of the items was altered to capture women's experiences of abortion services. Nine items measured different experiences of abortion care, and nine measured the subjective importance of these aspects. For example, 'I was treated with respect by the health care staff' (experience). 'It is important for me to be treated with respect by the health care staff' (subjective importance). A five- point Likert scale was used, where 1 denoted 'do not agree at all' and 5, denoted 'fully agree'. In the present study, Cronbach's alpha was 0.77 for the index of experience and 0.76 for the index of subjective importance.

\section{Statistical analyses}

Sample size estimation was based on a priori power analyses, previously presented by Wallin Lundell and colleagues ${ }^{22}$. Age was dichotomised into two categories: $\leq 24$ and $\geq 25$ years. According to the Official Statistics of Induced abortions in Sweden, most abortions during 2010 were performed in the age group 20 to 24 years, followed by women 25 to 29 years, then by women 30 to 34 years, and then by teenagers ${ }^{9}$. A suitable cut-off was considered to below 25 years and above, because most abortions are performed in the age group 20 to 24 
years, followed by the age group of 25 to 29 years. Alcohol users were compared with nonusers, and tobacco smokers and/or snuff users were compared with nonusers. In the analyses, women with a research diagnosis of PTSD or PTSS were categorised as one group. This group consisted of women with PTSD or PTSS only $(n=61)$, PTSD or PTSS and anxiety symptoms $(n=41)$, PTSD or PTSS and depressive symptoms $(n=6)$ and PTSD or PTSS and both anxiety and depressive symptoms $(n=74)$. Anxiety and depressive symptoms scores on the HADS were categorised as absent (score $=0-7$ ) or present (score $=8-21$ ). Women who scored high on the HADS (i.e., those who had anxiety and/or depressive symptoms) were included in one group. The group consisted of women with anxiety symptoms only $(\mathrm{n}=74)$, depressive symptoms only $(\mathrm{n}=39)$ and both anxiety and depressive symptoms $(\mathrm{n}=83)$.

The analysis of the QPP was conducted according to the instructions in the QPP manual ${ }^{16}$. An individual's score on a single item on the experience scale was compared with the group mean score for that item. The same procedure was performed with the matching item on subjective importance. Depending on the differences in the scores on the experience and subjective importance items, the quality of care was classified into one of three groups: deficiency, balance or excess (see Table 1).

Mean scores were also calculated for the nine experience items and for the nine subjective importance items. By comparing the mean scores of the two indexes, we obtained an overall assessment of the participants' perceptions of abortion care. The two indexes were calculated and classified as deficiency, balance or excess in the same way as described above (Table 1). For the statistical analyses, the three profile groups of deficiency, balance and excess were classified into two categories: deficiency was retained as one group, and balance and excess were combined to create a satisfactory group. 
Table 1 Examples of the classifications of quality of care

\begin{tabular}{|c|c|c|c|c|c|c|}
\hline \multirow{2}{*}{$\begin{array}{l}\text { Example } \\
\text { "Treated with respect by } \\
\text { the health care staff }\end{array}$} & \multicolumn{2}{|c|}{ Deficient } & \multicolumn{2}{|c|}{ Balance } & \multicolumn{2}{|c|}{ Excess } \\
\hline & Experience & $\begin{array}{l}\text { Subjective } \\
\text { importance }\end{array}$ & Experience & $\begin{array}{l}\text { Subjective } \\
\text { importance }\end{array}$ & Experience & $\begin{array}{l}\text { Subjective } \\
\text { importance }\end{array}$ \\
\hline $\begin{array}{l}\text { Score } \\
\text { Individual score in relation } \\
\text { to group mean score for } \\
\text { that item }\end{array}$ & Less & Greater & $\begin{array}{l}\text { Less } \\
\text { Greater }\end{array}$ & $\begin{array}{l}\text { Less } \\
\text { Greater }\end{array}$ & Greater & Less \\
\hline $\begin{array}{l}\text { Example } \\
\text { "Overall assessment of } \\
\text { abortion care }\end{array}$ & & & & & & \\
\hline $\begin{array}{l}\text { Score } \\
\text { Individual mean score for } \\
\text { the index in relation to the } \\
\text { group mean score for that } \\
\text { index }\end{array}$ & Less & Greater & $\begin{array}{l}\text { Less } \\
\text { Greater }\end{array}$ & $\begin{array}{l}\text { Less } \\
\text { Greater }\end{array}$ & Greater & Less \\
\hline
\end{tabular}

"The individual score for each experience item was compared with the subjective importance item for the same aspect of care.

"The individual mean score for the index of experience was compared with the mean score of subjective importance. In both cases,

participants' perspectives were then classified into three groups: deficient, balance and excess.

Perceptions of deficiency in care by sociodemographic variables, abortion method and mental health status were compared using chi square analysis or Fisher's exact test when needed. Multiple logistic regression analyses were performed to investigate whether mental health status (i.e., baseline PTSD/PTSS, anxiety and depressive symptoms) was independently associated with experiences of deficient abortion care. Adjustments were made for age, civil status, education and tobacco and alcohol use.

For women who underwent a medical abortion at one outpatient clinic, pain intensity was measured using of a VAS ranging from 0 to $10 \mathrm{~cm}$. In the present study, a VAS score of 0 was considered to be no pain, scores of 1-2 mild pain, 3-6 moderate pain and 7-10 severe pain $^{23}$. In the statistical analyses, the VAS scores were dichotomised: VAS scores of 1-6 were classified as mild to moderate pain and scores of 7-10 were classified as severe pain.

The alpha level was set at $p \leq 0.05$. SPSS Statistics for Windows, Version 20.0 (IBM Corp, Armonk, NY, USA) and used for all statistical analyses. 


\section{Results}

\section{Participants}

Overall, 2602 women were invited, and 1514 women participated in the study. In the present study, data were analysed from the baseline and the 3-month assessment. The response rate was $54 \%$ at the 3-month follow-up. The recruitment process is described in Figure 1. The drop-outs did not choose to participate further in the study, while the group of women who 'never reported to the study centre' were never given a choice to continue participation. They were excluded from the study because of these circumstances, and they were therefore not considered as drop-outs per se. A drop-out analysis is presented in a previous paper ${ }^{14}$ as well as details of the recruitment process ${ }^{13,14}$. 


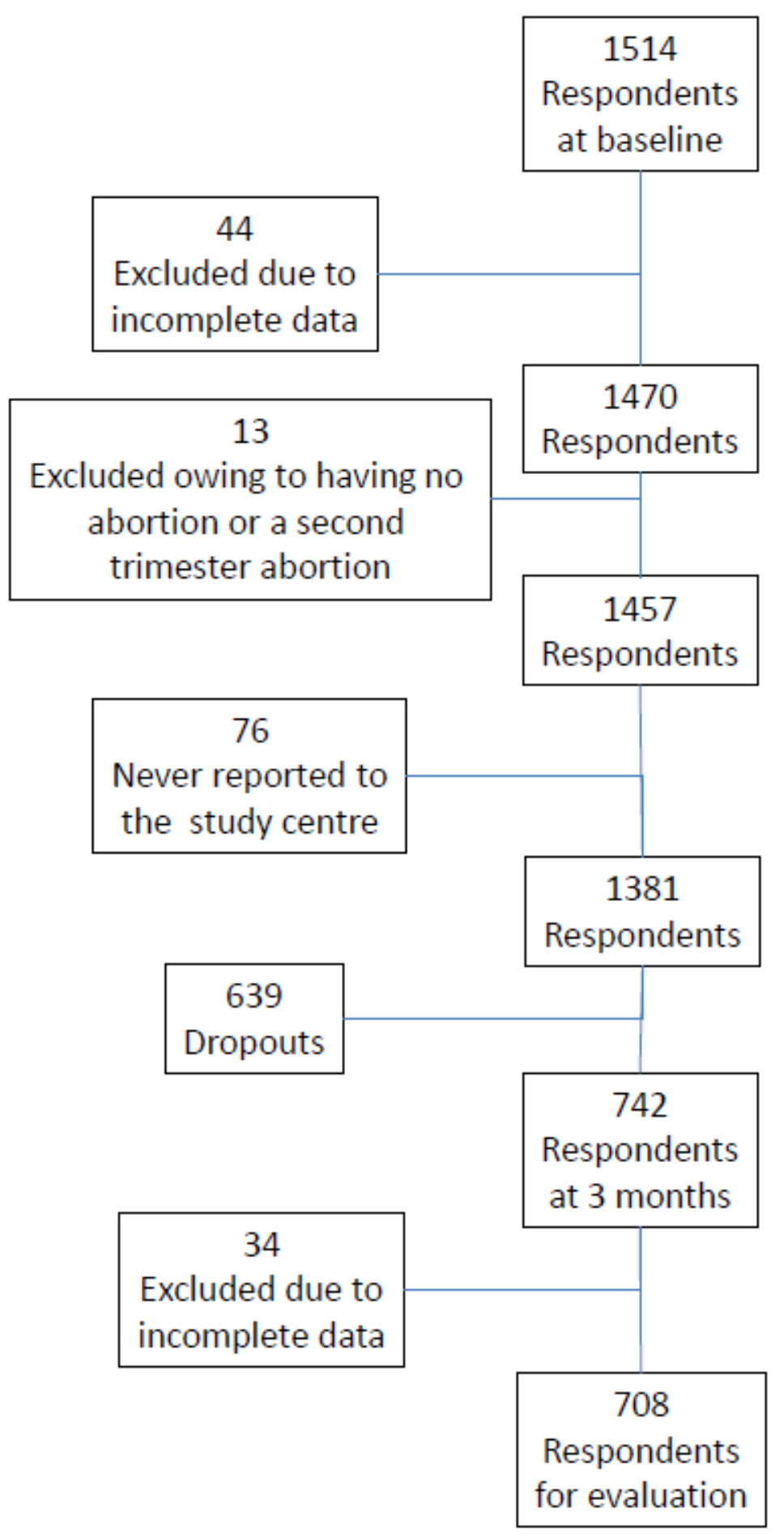

Figure 1 Flowchart of the respondents at baseline and the respondents and dropouts at the 3-month assessment.

Of the 708 participants in this study, 93\% were native Swedes. Ages ranged from 15 to 52 years, with a mean age of 28.7 ( $\mathrm{SD} \pm 7.4)$, and the most common occupational statuses were full-time worker or student. The majority of the women were married or cohabitant. Sixty- 
three percent had 12 years of highest completed education, and a third were tobacco users. PTSD (or PTSS), anxiety symptoms and depressive symptoms were prevalent in 25.7, 38.4 and $28.5 \%$ of the women, respectively. The most common abortion method was a medical one performed at home (Table 2).

\section{Perceived deficiencies in quality of abortion care in healthy women}

Of all the participating women, $16 \%$ reported the overall abortion care as being deficient. Perceived deficiencies differed between the QPP items, ranging from $11.7 \%$ for the possibility to have support from a partner when needed to $22.3 \%$ for respectful treatment by the health care staff (Table 2). 
Table 2 Baseline respondent characteristics and perceived deficiencies in abortion care at 3-month follow-up $(n=708)$.

\begin{tabular}{|c|c|c|}
\hline \multirow[t]{2}{*}{ Variable } & \multicolumn{2}{|c|}{ Respondents } \\
\hline & $n$ & $\%$ \\
\hline \multicolumn{3}{|l|}{ Baseline } \\
\hline \multicolumn{3}{|l|}{ Age } \\
\hline$\leq 24$ years & 250 & 35.3 \\
\hline$\geq 25$ years & 458 & 64.7 \\
\hline Unmarried/not cohabitant & 174 & 24.6 \\
\hline Completed education $\leq 12$ years & 444 & 62.7 \\
\hline Tobacco user & 235 & 33.2 \\
\hline Alcohol user & 580 & 81.9 \\
\hline No previous pregnancy & 276 & 39.0 \\
\hline No children & 340 & 52.3 \\
\hline PTSD or PTSS & 182 & 25.7 \\
\hline Anxiety symptoms & 272 & 38.4 \\
\hline Depressive symptoms & 202 & 28.5 \\
\hline Counselling before abortion & 297 & 41.9 \\
\hline \multicolumn{3}{|l|}{ Abortion method } \\
\hline Medical & 568 & 80.2 \\
\hline Surgical & 118 & 16.7 \\
\hline \multicolumn{3}{|l|}{ Place of abortion } \\
\hline Home & 380 & 53.7 \\
\hline Clinic & 304 & 42.9 \\
\hline \multicolumn{3}{|l|}{ Pain during the medical abortion procedure ${ }^{*}$} \\
\hline None $\left(\right.$ VAS $\left.^{* \prime}=0\right)$ & 11 & 8.6 \\
\hline Mild or moderate (VAS $=1-6$ ) & 89 & 69.5 \\
\hline Severe (VAS $=7-10)$ & 28 & 21.9 \\
\hline \multicolumn{3}{|l|}{ 3-month follow-up } \\
\hline \multicolumn{3}{|l|}{ Perceived deficiency in quality of abortion care in: } \\
\hline Acceptable waiting time for appointment & 151 & 21.3 \\
\hline Information about the procedure & 138 & 19.5 \\
\hline Participation in decision-making procedure & 103 & 14.5 \\
\hline Acceptable waiting time for the procedure & 105 & 14.8 \\
\hline Treatment with respect by the health care staff & 158 & 22.3 \\
\hline Receiving good care and support & 148 & 20.9 \\
\hline Possibility to have privacy and rest during the procedure & 105 & 14.8 \\
\hline Possibility to have support from partner, relative or friend when needed & 83 & 11.7 \\
\hline Effective analgesic & 112 & 15.8 \\
\hline Overall assessment of abortion care & 116 & 16.4 \\
\hline
\end{tabular}

Young, childless and primigravid women, and non-users of tobacco were more likely to assess the overall experience of abortion care as deficient (Table 3). Moreover, women who terminated their pregnancy at the abortion clinic were less satisfied with the abortion care they received than women who terminated their pregnancy at home. The reported perceptions of quality of care did not differ between women who had medical and those who had surgical abortions. Young women were the most critical, reporting deficiencies in all items (Table 3). 
Most women were satisfied with the analgesia, but young women were more likely to report inadequacies with this item (Table 3$)$. In the subgroup who rated pain intensity $(n=128)$, $22 \%$ experienced severe pain during the medical abortion procedure, and their pain alleviation was more often perceived as insufficient. Despite the lack of a significant difference, it is notable that women reporting severe pain were the most dissatisfied group on all items (Table 3). There were no differences regarding experiences of pain relief by the location of abortion (at home or at the clinic) or by the method of abortion. However, women who reported lack of pain relief were more likely to report discontentment in the overall assessment of abortion care, both in the subsample $(37 \%, p=0.01)$ and in the total sample $(39 \%, p<0.001)$.

\begin{tabular}{|c|c|c|c|c|c|c|c|c|c|c|c|c|c|}
\hline & \multirow{3}{*}{ Varisble } & \multicolumn{12}{|c|}{ Negative perceptions in quality of abortion care, by item } \\
\hline & & \multicolumn{3}{|c|}{$\begin{array}{l}\text { Treatment with respect by the } \\
\text { hesith care statf }\end{array}$} & \multicolumn{3}{|c|}{ Receiving good care and support } & \multicolumn{3}{|c|}{ Emective ansigecic } & \multicolumn{3}{|c|}{$\begin{array}{l}\text { Overall assessment of the } \\
\text { sbortion care }\end{array}$} \\
\hline & & $n$ & $\%$ & Pvalue & $\%$ & $\%$ & Prvalue & $n$ & $\%$ & P.value & $\mathrm{n}$ & $\%$ & Prvalue \\
\hline \multirow{3}{*}{ 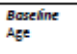 } & & & & & & & & & & & & & \\
\hline & $\leq 24$ & 78 & 31.3 & $\Phi .001$ & 63 & 255 & 0.033 & 92 & 210 & 0.007 & 53 & 21.2 & 0.011 \\
\hline & $=25$ & 80 & 179 & & 85 & 18.6 & & 60 & 13.2 & & 63 & 13.8 & \\
\hline \multirow{2}{*}{ Cinil state } & Cohobitant/meried & 117 & 225 & 0.752 & 102 & 19.7 & 0.178 & 81 & 157 & 0.597 & 32 & 15.8 & 0.533 \\
\hline & Not cohabitant & 37 & 214 & & 42 & 24.6 & & 30 & 17.4 & & 31 & 17.8 & \\
\hline \multirow{2}{*}{$\begin{array}{l}\text { Completed } \\
\text { eoucstion }\end{array}$} & S12 years & 89 & 200 & 0.049 & 83 & 188 & 0.053 & 69 & 157 & 0.779 & 67 & 19.1 & 0.203 \\
\hline & $>12$ yesrs & 69 & 26.4 & & 65 & 250 & & 43 & 165 & & 49 & 18.8 & \\
\hline \multirow{2}{*}{ Tosscco } & Tosecco user & 47 & 200 & 0.284 & 42 & 180 & 0.162 & 37 & 159 & 0.960 & 28 & 11.9 & 0.023 \\
\hline & Tosacco nonuser & 111 & 23.6 & & 106 & 226 & & 79 & 160 & & 88 & 18.6 & \\
\hline \multirow{2}{*}{ Alcohol } & Alcohol user & 134 & 23.1 & 0.280 & 121 & 210 & 0.990 & 96 & 16.7 & 0.271 & 92 & 15.9 & 0.424 \\
\hline & Alcohol nonuser & 24 & 188 & & 27 & 213 & & 16 & 127 & & 24 & 18.8 & \\
\hline \multirow{4}{*}{ Pregnancy } & No previous pregnanoy & 85 & 30.9 & $\infty .001$ & 74 & 27.1 & 0.002 & $9_{1}$ & 185 & 0.074 & 62 & 22.5 & $=0.001$ \\
\hline & Previous presnonoy & 65 & 16.6 & & 66 & 170 & & 92 & 13.4 & & 49 & 12.5 & \\
\hline & Without chilaren & 104 & 28.2 & $\$ 0.001$ & 89 & 243 & 0.013 & 64 & 17.4 & 0.172 & 72 & 19.5 & 0.019 \\
\hline & Whit dilidren & 46 & 151 & & 50 & 165 & & 41 & 13.6 & & 38 & 12.5 & \\
\hline \multirow[t]{9}{*}{ Abortion } & Counseling betore sbortion & & & & & & & & & & & & \\
\hline & res & 69 & 23.3 & 0.802 & 69 & 23.4 & 0.137 & 43 & 146 & 0.430 & 96 & 18.9 & 0.190 \\
\hline & No & 78 & 225 & & 64 & 18.6 & & 98 & 169 & & 52 & 15.0 & \\
\hline & Medical sbortion & 120 & 21.2 & 0.157 & 114 & 202 & 0.294 & 92 & 163 & 0.602 & 89 & 15.7 & 0.425 \\
\hline & Surgial soortion & 32 & 27.1 & 0.137 & 29 & 24.6 & 0.284 & $\begin{array}{l}72 \\
17\end{array}$ & $\begin{array}{l}1.3 .4 \\
14.4\end{array}$ & 0.002 & 22 & $\begin{array}{l}18.6 \\
18.6\end{array}$ & 0.425 \\
\hline & Abortion st home & 81 & 21.4 & 0.605 & 75 & 199 & 0.466 & 98 & 15.4 & 0.703 & 90 & $\begin{array}{l}13.2 \\
13.2\end{array}$ & 0.020 \\
\hline & Abortion st cinic & 70 & 230 & & 67 & 222 & & 90 & 169 & & 60 & 19.7 & \\
\hline & vas" $0.6^{\circ}$ & 14 & 1577 & 0.057 & 13 & 14.6 & 0.378 & 7 & 79 & $\leq 0.001$ & 12 & 13.5 & 0.159 \\
\hline & VAS $7-10$ & 9 & 32.1 & & 6 & 222 & & 10 & 37.9 & & 7 & 25.0 & \\
\hline
\end{tabular}


Perceived deficiencies in quality of abortion care in women with mental or posttraumatic stress

Women with posttraumatic stress were more likely to experience in the overall satisfaction with abortion care. They were also dissatisfied concerning being treated with respect by the health care staff, receiving good care and support, having possibilities for privacy and rest during the procedure and having the possibility to have support from a partner or another significant person. Additionally, they reported insufficient pain relief more often than did women without posttraumatic stress (not significant). The analyses revealed no differences in the content of abortion care between the healthy comparison group and women with anxiety and/or depressive symptoms (Table 4).

\begin{tabular}{|c|c|c|c|c|c|c|c|c|}
\hline \multirow[b]{2}{*}{ Negative perceptions in quality of abortion care by item } & \multicolumn{2}{|c|}{$\begin{array}{c}\text { Comparison } \\
\text { group } \\
(\mathrm{n}=\mathbf{3 3 0})\end{array}$} & \multicolumn{3}{|c|}{$\begin{array}{c}\text { PTSD/PTSS } \\
(n=182)\end{array}$} & \multicolumn{3}{|c|}{$\begin{array}{l}\text { Anxiety and/or } \\
\text { depressive } \\
\text { symptoms } \\
(n=196)\end{array}$} \\
\hline & $\mathrm{n}$ & $\%$ & $\mathrm{n}$ & $\%$ & P-value & $\mathrm{n}$ & $\%$ & P-value \\
\hline Acceptable waiting time for appointment & 73 & 21.1 & 40 & 22.1 & 0.995 & 38 & 19.5 & 0.475 \\
\hline Information about the procedure & 61 & 18.5 & 34 & 18.8 & 0.934 & 43 & 21.9 & 0.336 \\
\hline Participating in decision-making procedure & 42 & 12.7 & 31 & 17.2 & 0.166 & 30 & 15.3 & 0.405 \\
\hline Acceptable waiting time for the procedure & 46 & 14.0 & 27 & 14.9 & 0.773 & 32 & 16.3 & 0.465 \\
\hline Treatment with respect by the health care staff deficiency & 60 & 18.2 & 50 & 27.6 & 0.013 & 48 & 24.5 & 0.083 \\
\hline Receiving good care and support & 55 & 16.8 & 51 & 28.5 & 0.002 & 42 & 21.4 & 0.184 \\
\hline Possibility to have privacy and rest during the procedure & 35 & 10.7 & 39 & 21.9 & 0.001 & 31 & 16.0 & 0.082 \\
\hline Possibility to have support from partner, relative or friend when needed & 31 & 9.5 & 32 & 18.1 & 0.006 & 20 & 10.2 & 0.796 \\
\hline Effective analgesic & 48 & 14.8 & 39 & 21.5 & 0.053 & 25 & 12.8 & 0.521 \\
\hline Overall assessment of abortion care & 44 & 13.3 & 38 & 20.9 & 0.026 & 34 & 17.3 & 0.210 \\
\hline
\end{tabular}

Following adjustments for relevant confounders, PTSD/PTSS was significantly associated with increased reporting of discontentment of overall quality of care (adjusted odds ratio 
[AOR] 1.94, CI 95\% 1.17-3.21). Anxiety and/or depressive symptoms, however, were not associated with increased report of overall deficient abortion care (AOR 1.29, CI 95\% $0.78-$ 2.15).

\section{Discussion}

\section{Findings}

Suffering from PTSD or PTSS was associated with increased reporting of deficient abortion care. Besides dissatisfaction with the overall abortion care, women with PTSD/PTSS also reported discontentment in care and support during the abortion process and dissatisfaction in being treated with respect by the health care staff. Other common deficiencies included the possibility of having privacy and rest during the procedure and the possibility to have the support of a partner or another significant person during the abortion. Additionally, women with PTSD/PTSS were more likely to experience insufficiencies in pain alleviation (not significant). Women with anxiety and/or depressive symptoms did not experience abortion care as more defective than did the healthy comparison group.

\section{Strengths and weaknesses of the study}

The strengths of the present study include the multi-centre study design, which made it possible to evaluate abortion care at six outpatient clinics in hospitals in large- and mid-sized cities across the country, and the large size of the study sample. The major limitation is the high dropout rate in the study. We have no information on how the dropouts experienced abortion care. Previous dropout analyses in this cohort have suggested that women with PTSD and/or those with more pronounced anxiety and depressive symptoms at baseline were less likely to continue participation in the study ${ }^{14}$. Additionally, others have reported that young women more often drop out from abortion studies ${ }^{24}$. It is therefore possible that deficiencies in the abortion services might be underestimated. Another limitation involves the way in which the QPP was used. In the original QPP, the items and the theoretical framework of the 
questionnaire were developed based on patient interviews. The QPP has subsequently been modified to apply to many contexts of care, and all questions have been derived according to the patient's perspective and formulated in words used by patients, strengthening the validity of the questionnaire ${ }^{16}$. However, no questionnaire has been developed for abortion services. Therefore, the QPP questions intended for outpatient clinics were used in the present study, but the phrasing of these items was altered to capture the women's experiences of abortion services. Ultimately, this may have affected the psychometric properties of the questionnaire. Furthermore, self-reported inventories have several limitations, such as the potential influence of the question wording, questionnaire format and number of items on the respondent's answers $^{25}$. Additionally, it is evident that age and health status can affect the participants' ratings, and this should be kept in mind when interpreting the results ${ }^{26}$. Because there was a period of 3 months between the abortion and the assessment of the quality of the care, recall bias may also be a possibility.

\section{Differences in results in relation to other studies}

In accordance with previous studies ${ }^{1,2,5,27}$, we found that young women were dissatisfied with abortion services. They expressed deficiencies in a number of items, including treatment with respect by the health care staff, receipt of good care and support and effective analgesia as well as the overall assessment of quality of the abortion care. Young age has previously been associated with low patient satisfaction ${ }^{28}$, but contradictory results have also been reported ${ }^{5}$. Findings from previous Swedish studies suggest that younger women, particularly teenagers, experience negative attitudes about their pregnancies from health care staff. Furthermore, past research has described experiences of paternalistic attitudes from health care staff such as overly coercive contraceptive counselling, concerns about the failure to address difficulties of finding a suitable contraceptive method, worries about the side effects of contraceptives and feelings of having no possibility to discuss the unwanted pregnancy ${ }^{29,30}$ 
The large number of women with only 12 years of highest completed education might be due to the young age in our sample. Many of the women were ungraduated students so their reported educational level will be upper secondary school ( $\leq 12$ years). The results are in line with Statistics Sweden (2012) who report that $30 \%$ of the Swedish women in the ages between 22 and 23 years are under higher education (university studies), compared with $22 \%$ of the men. Furthermore, $30 \%$ of Swedes in the age range of 25 to 64 years have some form of higher education; in year 2011 this figure was $38 \%{ }^{31}$.

Women who had a medical abortion at the clinic reported more dissatisfaction with the abortion services than did women who chose a home abortion. According to regulations from the Swedish government, women have the right to choose an abortion method up to the 9th gestational week. Women should be informed on the surgical and medical method and the option to have a medical abortions at home. In collaboration with a physician or a midwife, the women then can make an informed choice of a suitable method and place. This is the ideal way but we cannot guarantee that all women in our study were offered this option before the 9th gestational week. Studies of home abortions are few, and concerns have been raised, from a clinical point of view, that severe pain during medical abortions in home settings may place women at risk for traumatic experiences.

However, the results of the present study revealed no indications of inadequate pain alleviation in women who had a home abortion. Studies of medical abortion in home settings indicate that women appreciate the privacy, control and the social support they are able to get from their partner or another significant person during the abortion process ${ }^{8,32-34}$ They are more likely to be satisfied, to choose the method again and to recommend the method to a friend than are women who chose medical abortion in the clinic setting ${ }^{34,35}$. The support and care that women received from their partners, parents or friends may have influenced how they evaluated 'good care and support' in this study. 
One-fifth of women in the medical abortion subsample stated that their pain experience was severe. It is clinical practice to prescribe analgesics for women undergoing medical abortions as well as surgical abortions. The most common analgesics prescribed for women undergoing medical abortion was a combination of 1 to 2 tablets containing Paracetamol $500 \mathrm{mg}+$ codeine $30 \mathrm{mg}$ (Citodon) in combination with 2 tablets of Diclofenac $50 \mathrm{mg}$. Perceived pain, either psychological or physical, is central in the traumatic experience leading to posttraumatic stress reactions. Thus, proper watchfulness and pain alleviation should be prioritised to avoid painful, experiences or re-traumatisation in women with previous traumatic reactions. Women with PTSD/PTSS were more likely to experience insufficiencies in pain alleviation. This might be due to pain adjustment, because study findings have demonstrated that the PTSD hyperarousal symptom cluster is associated with pain outcomes such as pain intensity and disability in patients with chronic pain ${ }^{36}$. Previous studies have demonstrated that experiencing severe pain during labour is a strong risk factor for negative experiences of childbirth ${ }^{37}$. Additionally, women who had a negative overall experience of childbirth had high pain scores and did not forget the intensity of the pain years later, in contrast to women with a positive experience, who forgot the labour pain over time ${ }^{38}$. Consequently, inadequate pain alleviation may also be a risk factor for negative experiences to take into account in abortion care.

\section{Relevance of the findings: Implication for healthcare personnel and policymakers}

Although women who presented to the abortion clinic with ongoing PTSD or PTSS were more prone to report perceived problems with the quality of abortion care, it is currently unknown whether these negative experiences might be a risk factor for subsequent mental health problems post-abortion. The findings from the present study suggest that further improvements are possible, especially for women who present at the abortion clinic with ongoing PTSD or PTSS. The woman's history is the foundation of consultation, enabling 
individualisation of care according to different needs ${ }^{39}$. Our results underline the importance of clinical awareness of patients' ongoing mental state for patient-centred care. To provide women with good care and support, it should be mandatory that all women are given the possibility for privacy and rest during the procedure, and women should also be able to bring a partner, friend or relative for support during the abortion. Furthermore, midwives currently perform early medical abortions in Sweden ${ }^{40}$. With this practice, midwifes are responsible for the entire abortion process from receiving the first call for an appointment to follow-up. This allows the women to meet the same midwife throughout the whole process ${ }^{10}$. This continuity, together with a patient-centred attitude, may increase the possibilities for women to receive good care. Their different abortion care needs, whether due to mental health state, age or other circumstances, will more likely be discovered. In theory, this practice should improve the care and support provided during the abortion process for all women.

\section{Unanswered questions and future research}

More studies are needed about how vulnerable women at risk for negative experiences of abortion will be identified, although it is a challenge for healthcare personnel to identify these women. One way might be to ask specific questions as has been suggested in a previous study 41. For example, questions about social support, coping strategies and prior mental health status to narrow down women at risk of mental distress following abortion. Respecting women's integrity, it is a true challenge to ask these questions in such a way so that they are not intrusive to women, and at the same time the women should not be made to feel that they should question their decision to terminate the pregnancy.

\section{Conclusion}

Women with posttraumatic stress more often perceived the quality of abortion care as deficient. Although these women should be given extra care and support, our findings also stress that relatively simple efforts may improve abortion care for women, particularly those 
with PTSD or PTSS. For instance, a patient-centred attitude may increase the feeling of being treated with respect and receiving good care and support. Furthermore, it should be mandatory that all women are given the possibility for privacy and rest during the procedure, and women should be able to bring a significant person for support during the abortion.

\section{Declaration of interest}

Funding for this project was provided by the Marianne and Marcus Wallenberg Foundation, the Medical Faculty of Uppsala Universities, the Family Planning Foundation at Uppsala University, the Regional Research Committees of Uppsala and Örebro Counties Councils and Sophiahemmet Foundation. 


\section{References}

1. Zapka JG, Lemon S, Peterson LE, et al. The silent consumer: women's reports and ratings of abortion services. Med Care 2001;39(1):50-60.

2. Taylor D, Postlethwaite D, Desai S, et al. Multiple determinants of the abortion care experience: from the patient's perspective. Am J Med Qual 2013;28(6):510-8.

3. Becker D, Diaz-Olavarrieta C, Juarez C, et al. Clients' perceptions of the quality of care in Mexico city's public-sector legal abortion program. Int Perspect Sex Reprod Health 2011;37(4):191201.

4. Oliveras E, Larsen U, David PH. Client satisfaction with abortion care in three Russian cities. J Biosoc Sci 2005;37(5):585-601.

5. Makenzius M, Tyden T, Darj E, et al. Women and men's satisfaction with care related to induced abortion. Eur J Contracept Reprod Health Care 2012;17(4):260-9.

6. Abdel-Aziz E, Hassan IM, Al-Taher H. Assessment of women's satisfaction with medical termination of pregnancy. J Obstet Gynaecol 2004;24(4):429-33.

7. Slade $P$, Heke $S$, Fletcher J, et al. Termination of pregnancy: patients' perceptions of care. J Fam Plann Reprod Health Care 2001;27(2):72-7.

8. Kero A, Wulff M, Lalos A. Home abortion implies radical changes for women. Eur J Contracept Reprod Health Care 2009;14(5):324-33.

9. The National Board of Health and Welfare. Official statistics of Sweden, Statistics - Health and Medical Care, Induced abortions 2011: The National Board of Health and Welfare, 2012.

10. The National Board of Health and Welfare. Medical abortion, distribution of tasks - practice and regulations [ Medicinska aborter, fördelning av arbetsuppgifter - praxis och regelverk ].[In Swedish]. Stockholm: The National Board of Health and Welfare, 2008.

11. Barbosa CD, Balp MM, Kulich $\mathrm{K}$, et al. A literature review to explore the link between treatment satisfaction and adherence, compliance, and persistence. Patient Prefer Adherence 2012;6:39-48.

12. Frans Ö, Rimmö P-A, Åberg L, et al. Trauma exposure and post-traumatic stress disorder in the general population. Acta Psychiatr Scand 2005;111(4):291-90.

13. Wallin Lundell I, Sundstrom Poromaa I, Frans O, et al. The prevalence of posttraumatic stress among women requesting induced abortion. Eur J Contracept Reprod Health Care 2013;18(6):480-8.

14. Wallin Lundell I, Georgsson Ohman S, Frans O, et al. Posttraumatic stress among women after induced abortion: a Swedish multi-centre cohort study. BMC Womens Health 2013;13(1):52.

15. Zigmond A, Snaith, RP. The Hospital Anxiety and Depression Scale. Acta Psychiatr Scand 1983;67:361-70.

16. Wilde Larsson B. Kvalitet Ur Patientens Perspektiv. Stockholm: Vårdförbundet, 2001. [In Swedish]. 
17. Wilde Larsson B, Larsson G. Development of a short form of the Quality from the Patient's Perspective (QPP) questionnaire. J Clin Nurs 2002;11(5):681-7.

18. American Psychological Association. Report of the Task Force on Mental Health and Abortion. Washington, DC. 2008.

19. Breslau N, Lucia VC, Davis GC. Partial PTSD versus full PTSD: an empirical examination of associated impairment. Psychol Med 2004;34(7):1205-14.

20. Bjelland I, Dahl AA, Haug TT, et al. The validity of the Hospital Anxiety and Depression Scale. An updated literature review. J Psychosom Res 2002;52(2):69-77.

21. Lisspers J, Nygren A, Soderman E. Hospital Anxiety and Depression Scale (HAD): some psychometric data for a Swedish sample. Acta Psychiatr Scand 1997;96(4):281-6.

22. Wallin Lundell I, Sundstrom Poromaa I, Frans $O$, et al. The prevalence of posttraumatic stress among women requesting induced abortion. Eur J Contracept Reprod Health Care 2013.

23. Collins SL, Moore RA, McQuay HJ. The visual analogue pain intensity scale: what is moderate pain in millimetres? Pain 1997;72(1-2):95-7.

24. Soderberg $\mathrm{H}$, Andersson $\mathrm{C}$, Janzon L, et al. Selection bias in a study on how women experienced induced abortion. Eur J Obstet Gynecol Reprod Biol 1998;77(1):67-70.

25. Kazdin AE. Research design in clinical psychology. Harlow: Pearson new international edition, 2010.

26. Crow R, Gage H, Hampson S, et al. The measurement of satisfaction with healthcare: implications for practice from a systematic review of the literature. Health Technol Assess 2002;6(32):1244.

27. Abdel-Aziz E, Hassan I, Al-Taher HM. Assessment of pain associated with medical abortion. Int J Gynaecol Obstet 2004;84(3):264-5.

28. Rahmqvist M. Patient satisfaction in relation to age, health status and other background factors: a model for comparisons of care units. Int J Qual Health Care 2001;13(5):385-90.

29. Ekstrand M, Larsson M, Von Essen L, et al. Swedish teenager perceptions of teenage pregnancy, abortion, sexual behavior, and contraceptive habits--a focus group study among 17-year-old female high-school students. Acta Obstet Gynecol Scand 2005;84(10):980-6.

30. Ekstrand M, Tyden T, Darj E, et al. An illusion of power: qualitative perspectives on abortion decision-making among teenage women in Sweden. Perspect Sex Reprod Health 2009;41(3):173-80.

31. Statistics Sweden. Yearbook of Educational Statistics 2012. [Statistiska centralbyrån. Utbildningsstatistisk årsbok 2012]. [In Swedish]. Accessed 19 November 2014 from: http://www.scb.se/statistik/_publikationer/UF0524_2011A01_BR_00_UF01BR1101.pdf

32. Makenzius $M$, Tyden T, Darj E, et al. Autonomy and dependence--experiences of home abortion, contraception and prevention. Scand J Caring Sci 2013;27(3):569-79.

33. Kopp Kallner H, Fiala C, Gemzell-Danielsson K. Assessment of significant factors affecting acceptability of home administration of misoprostol for medical abortion. Contraception 2012;85(4):394-7.

34. Cameron S, Glasier A, Dewart H, et al. Women's experiences of the final stage of early medical abortion at home: results of a pilot survey. J Fam Plann Reprod Health Care 2010;36(4):2136.

35. Ngo TD, Park MH, Shakur H, et al. Comparative effectiveness, safety and acceptability of medical abortion at home and in a clinic: a systematic review. Bull World Health Organ 2011;89(5):360-70.

36. Lopez-Martinez AE, Ramirez-Maestre C, Esteve R. An examination of the structural link between post-traumatic stress symptoms and chronic pain in the framework of fear-avoidance models. Eur J Pain 2014;18(8):1129-38.

37. Waldenstrom $U$, Hildingsson I, Rubertsson C, et al. A negative birth experience: prevalence and risk factors in a national sample. Birth 2004;31(1):17-27.

38. Waldenstrom $U$, Schytt E. A longitudinal study of women's memory of labour pain--from 2 months to 5 years after the birth. BJOG 2009;116(4):577-83. 
39. Gallagher K, Porock D, Edgley A. The concept of 'nursing' in the abortion services. J Adv Nurs 2010;66(4):849-57.

40. Vårdfokus. Certifierad att göra ultraljud. [In Swedish] Accessed 19 November 2014 from: https://vardforbundet.se/Vardfokus/Webbnyheter/2014/April/Tar-over-ultraljudet/.

41. Harris AA. Supportive counseling before and after elective pregnancy termination. Journal of midwifery \& women's health 2004;49(2):105-12. 